\title{
Genetic connectivity between Atlantic bluefin tuna larvae spawned in the Gulf of Mexico and in the Mediterranean Sea
}

\author{
Carolina Johnstone ${ }^{\text {Corresp., } 1}$, Montse Perez ${ }^{2}$, Estrella Malca ${ }^{3,4}{ }^{4}$ Jose Maria Quintanilla ${ }^{1}$, Trika Gerard $^{4}$, Diego \\ Lozano-Peral $^{5}$, Francisco Alemany ${ }^{6}$, John Lamkin ${ }^{4}$, Alberto Garcia ${ }^{1}$, Raúl Laiz-Carrión ${ }^{1}$ \\ ${ }^{1}$ Centro Oceanográfico de Málaga, Centro Nacional Instituto Español de Oceanografía, Consejo Superior de Investigaciones Científicas, Fuengirola, \\ Málaga, Spain \\ 2 Centro Oceanográfico de Vigo, Instituto Español de Oceanografía, Vigo, Pontevedra, Spain \\ 3 Cooperative Institute for Marine and Atmospheric Studies, University of Miami, Miami, Florida, United States of America \\ ${ }^{4}$ Southeast Fisheries Science Center, National Marine Fisheries Service., National Oceanic and Atmospheric Administration, Miami, Florida, United States \\ of America \\ ${ }^{5}$ Centro de Supercomputación y Bioinnovación, Universidad de Málaga, Málaga, Spain \\ 6 International Commision for the Conservation of Atlantic Tunas, Madrid, Spain
}

Corresponding Author: Carolina Johnstone

Email address: carolina.johnstone@ieo.es

The highly migratory Atlantic bluefin tuna (ABFT) is currently managed as two distinct stocks, in accordance with natal homing behavior and population structuring despite the absence of barriers to gene flow. Larval fish are valuable biological material for tuna molecular ecology. However, they have hardly been used to decipher the ABFT population structure although providing the genetic signal from successful breeders. For the first time, cooperative field collection of tuna larvae during 2014 in the main spawning area for each stock, the Gulf of Mexico (GOM) and the Mediterranean Sea (MED), enabled us to assess the ABFT genetic structure in a precise temporal and spatial frame exclusively through larvae. Partitioning of genetic diversity at nuclear microsatellite loci and in the mitochondrial control region in larvae spawned contemporarily resulted in low significant fixation indices supporting connectivity between spawners in the main reproduction area for each population. No structuring was detected within the GOM after segregating nuclear diversity in larvae spawned in two hydrographically distinct regions, the eastern GOM (eGOM) and the western GOM (wGOM), with the larvae from eGOM being more similar to those collected in the MED than the larvae from wGOM. We performed clustering of genetically characterized ABFT larvae through Bayesian analysis and by Discriminant Analysis of Principal Components (DAPC) supporting the existence of favorable areas for mixing of ABFT spawners from Western and Eastern stocks, leading to gene flow and apparent connectivity between weakly structured populations. Our findings suggest that the eastern GOM is more prone for the mixing of breeders from the two ABFT populations. Conservation of this valuable resource exploited for centuries calls for intensification of 
tuna ichthyoplankton research and standardization of genetic tools for monitoring population dynamics. 


\section{Genetic connectivity between Atlantic bluefin tuna}

\section{2 larvae spawned in the Gulf of Mexico and in the}

\section{Mediterranean Sea.}

5 Carolina Johnstone ${ }^{1}$, Montse Pérez ${ }^{2}$, Estrella Malca ${ }^{3,4}$, José María Quintanilla ${ }^{1}$, Trika Gerard ${ }^{4}$,

6 Diego Lozano-Peral ${ }^{5}$, Francisco Alemany ${ }^{6}$, John Lamkin ${ }^{4}$, Alberto García ${ }^{1}$, and Raúl Laiz-

7 Carrión $^{1}$

$9{ }^{1}$ Centro Oceanográfico de Málaga, Centro Nacional Instituto Español de Oceanografía, Consejo

10 Superior de Investigaciones Científicas, Fuengirola (Málaga), Spain. ${ }^{2}$ Centro Oceanográfico de

11 Vigo, Centro Nacional Instituto Español de Oceanografía, Consejo Superior de Investigaciones

12 Científicas, Vigo (Pontevedra), Spain. ${ }^{3}$ Cooperative Institute for Marine and Atmospheric

13 Studies, University of Miami, Miami, Florida, United States of America. ${ }^{4}$ Southeast Fisheries

14 Science Center, National Marine Fisheries Service, National Oceanic and Atmospheric

15 Administration, Miami, Florida, United States of America. ${ }^{5}$ Centro de Supercomputación y

16 Bioinnovación, Universidad de Málaga, Málaga, Spain. ${ }^{6}$ International Commission for the

17 Conservation of Atlantic Tunas. Madrid, Spain.

18 Corresponding Author:

19 Carolina Johnstone ${ }^{1}$

20 Centro Oceanográfico de Málaga, Puerto Pesquero s/n, Fuengirola (Málaga), 29640 Spain.

21 Email address: carolina.johnstone@ieo.es 


\section{Abstract}

The highly migratory Atlantic bluefin tuna (ABFT) is currently managed as two distinct stocks, in accordance with natal homing behavior and population structuring despite the absence of barriers to gene flow. Larval fish are valuable biological material for tuna molecular ecology. However, they have hardly been used to decipher the ABFT population structure although providing the genetic signal from successful breeders. For the first time, cooperative field collection of tuna larvae during 2014 in the main spawning area for each stock, the Gulf of Mexico (GOM) and the Mediterranean Sea (MED), enabled us to assess the ABFT genetic structure in a precise temporal and spatial frame exclusively through larvae. Partitioning of genetic diversity at nuclear microsatellite loci and in the mitochondrial control region in larvae spawned contemporarily resulted in low significant fixation indices supporting connectivity between spawners in the main reproduction area for each population. No structuring was detected within the GOM after segregating nuclear diversity in larvae spawned in two hydrographically distinct regions, the eastern GOM (eGOM) and the western GOM (wGOM), with the larvae from eGOM being more similar to those collected in the MED than the larvae from wGOM. We performed clustering of genetically characterized ABFT larvae through Bayesian analysis and by Discriminant Analysis of Principal Components (DAPC) supporting the existence of favorable areas for mixing of ABFT spawners from Western and Eastern stocks, leading to gene flow and apparent connectivity between weakly structured populations. Our findings suggest that the eastern GOM is more prone for the mixing of breeders from the two ABFT populations. Conservation of this valuable resource exploited for centuries calls for intensification of tuna ichthyoplankton research and standardization of genetic tools for monitoring population dynamics. 
45

46

47

48

49

50

51

52

53

54

55

\section{Introduction}

Bluefin tuna are epipelagic oceanic species that have been exploited globally for centuries (Muhling et al., 2017). Regional fisheries organizations manage Pacific bluefin Thunnus orientalis (Temminck and Schlegel, 1844) as one stock, Southern bluefin T. maccoyii (Castelnau, 1872) also as one stock, and Atlantic bluefin tuna (ABFT) T. thynnus (Linnaeus, 1758) as two, Western and Eastern, stocks. Each of these stocks is considered a distinct population (Kumar \& Kocour, 2015). Although individual juvenile and adult fish are capable of trans-Atlantic migrations and share feeding grounds in the North Atlantic Ocean, the Western ABFT primarily spawn in the Gulf of Mexico (GOM) and the Eastern ABFT in the Mediterranean Sea (MED) (Muhling et al., 2017). Despite additional spawning areas for ABFT have been recently discovered in the Slope Sea and the Bay of Biscay (Richardson et al., 2016; Rodriguez, Johnstone \& Lozano-Peral, 2021), the GOM and the MED are still considered the main grounds to which the adults return to breed, with regional currents linking larval and juvenile nursery habitats (Muhling et al., 2017).

Overexploitation of this valuable fishery resource resulted in sharp decreases in abundance from the 1960s onward. This led to the implementation of strict management measures after 2007 by the International Commission for the Atlantic Tuna (ICCAT). The 2017 assessment results from the virtual population analysis (VPA) indicated that the spawning stock biomass (SSB) exhibited a substantial increase from the late 2000s (ICCAT, 2020), which has allowed to presently raise catch quotas, in spite the species is still currently listed as endangered by the International Union for Conservation of Nature (IUCN, 2020). Increasing our understanding of the connectivity between ABFT populations is crucial for conservation of ABFT. The existence of weak structuring between Western and Eastern stocks is supported by 
68

69

70

71

72

73

74

numerous studies that have assessed the population structure of ABFT through different approaches such as analysis of genetic diversity with multiple applications for conservation and fisheries management (Abdul-Muneer, 2014; Ovenden et al., 2015; Cuéllar-Pinzón et al., 2016). In particular, a variety of genetic markers have been employed to assess ABFT population dynamics including the fast-evolving maternally inherited mitochondrial DNA (mtDNA) (Carlsson et al., 2004, 2007; Alvarado Bremer et al., 2005; Boustany, Reeb \& Block, 2008), codominant highly polymorphic microsatellite loci (Carlsson et al., 2004, 2007; Riccioni et al., 2010, 2013; Antoniou et al., 2017), and more recently high-throughput sequencing of highly abundant single nucleotide polymorphisms or SNPs (Antoniou et al., 2017; Puncher et al., 2018; Rodríguez-Ezpeleta et al., 2019). Subtle structuring of ABFT populations across the Atlantic Ocean is the general conclusion of genetic studies, with significant $\mathrm{F}_{\mathrm{ST}}$ fixation indices that estimate partitioning of genetic diversity on a zero to one scale ranging from 0.005 to 0.012 (Puncher et al., 2018). The analysis of the phylogenetic signal of mtDNA suggests a dramatic reduction in ABFT population size during Pleistocene glaciations, followed by sudden population expansion with an increase in gene flow to levels resulting in homogenization of stocks (Alvarado Bremer et al., 2005). Other disciplines besides genetics have confirmed that the two ABFT populations are indeed highly mixed. Estimation of natal origin through otolith microchemistry demonstrated substantial intermingling of individuals from both populations in North Western Atlantic waters (Rooker et al., 2003, 2008a); spatio-temporal distributions of electronically tagged ABFT revealed overlapping of foraging grounds and provided evidence for spawning fidelity to the MED (Block et al., 2005), and a fisheries model predicts that mixing depends on season and location (Taylor et al., 2011). A recently developed population assignment method combining genetic (SNPs) and environmental (otolith microchemistry) 
91 markers revealed complexity in ABFT structure (Brophy et al., 2020). There is thus mounting

92 evidence supporting the highly-mixed nature of ABFT populations. Nevertheless, certain

93 questions still remain unresolved, including the level of gene flow or connectivity between

94 populations and the exchange rate between stocks.

95
Larval cooperative studies have provided insights into multiple aspects of tuna larval ecology and biology, particularly growth and food web dynamics (Laiz-Carrion et al., 2015; Malca et al., 2017; Laiz-Carrión et al., 2019). Intensification of cooperative ichthyoplankton prospection surveys to collect ABFT larvae is currently required after the incorporation of larval indexes into stock assessment (Ingram et al., 2017), providing a valuable opportunity to gain further knowledge on other aspects such as tuna population dynamics. As far as we are aware, ABFT population genetic structuring has not yet been assessed exclusively from larval ABFT ensuring both correct geographical assignment and representation of genetic features of successful breeders. The study of ABFT population genetics has mostly focused on adults collected in Eastern and Western stocks (Alvarado Bremer et al., 2005) or within the Mediterranean Sea (Riccioni et al., 2010, 2013; Viñas et al., 2011; Vella et al., 2016; Antoniou et al., 2017). Juveniles (young-of-the-year, YOY) collected in nursery areas have occasionally been characterized exclusively or together with adults (Boustany, Reeb \& Block, 2008), and with larvae in only a few interesting studies (Carlsson et al., 2004, 2007; Puncher et al., 2018; Rodríguez-Ezpeleta et al., 2019). The use of YOY juveniles collected in nursery habitats reduces the risk of including migrants in the incorrect subpopulation. However, these juveniles are strong swimmers and can move thousands of kilometres away from their spawning location.

Conveniently, collection of larvae in spawning grounds completely eliminates this potential error and provides the genetic signal of spawners. The movement of larval ABFT ( $<20$ days age) is 
114 physiologically limited by multiple factors including a lack of morphological development of fin

115 complements and muscle required for locomotion outside of the corresponding spawning

116 grounds. Full sibling removal is however recommended to accurately estimate genetic diversity,

117 at least for larvae of other animals (Goldberg \& Waits, 2010). The aim of our study was to assess

118 ABFT genetic structure in a precise temporal and spatial frame exclusively through larvae

119 collected in the two main spawning grounds.

Management and conservation of ABFT requires continuous research concerning the

121 population dynamics and exchange between Western and Eastern stocks that can be achieved

122 through tagging studies (Rooker et al., 2019) or genetic tools for traceability (Puncher et al.,

123 2018; Rodríguez-Ezpeleta et al., 2019). Genetic structure between ABFT collected in Western

124 and Eastern stocks is herein assessed by analyzing diversity in larvae through two differently

125 inherited markers, mtDNA control region sequences and nuclear microsatellite loci, following

126 the approach of Carlsson et al. (2007). Fast evolving mtDNA is maternally inherited and

127 provides the evolutionary signal for this highly migratory species, for which past hybridization

128 events with albacore have been reported (Alvarado Bremer et al., 2005). Highly polymorphic

129 nuclear microsatellite loci with Mendelian inheritance allow evaluating population connectivity.

130 We analyzed larvae collected only during the 2014 spawning season to capture a snapshot of

131 gene flow between ABFT breeders in the main spawning ground of each stock without blurring

132 the image by mixing years with different stock mixing rates. Individual-based clustering analysis

133 of larval ABFT genetic diversity indicate apparent connectivity between the GOM and MED

134 spawning grounds that could support the hypothesis of mixing of breeders belonging to different 135 stocks. 
136

137

138

139

140

141

142

143

144

145

146

147

148

149

150

151

152

153

154

155

156

157

\title{
Materials \& Methods
}

\author{
Field collection of ABFT larvae
}

We conducted larval ABFT collections during the peak of the reproductive season in the two main spawning areas for ABFT, the GOM and the MED (Fig. 1). The GOM was divided into subregions separated at $90^{\circ} \mathrm{W}$ meridian and designated as eastern (eGOM) and western (wGOM) (Muller-Karger et al., 2015). A total of 76 stations were sampled in the GOM cruise "WS1405" (approved by the National Oceanic and Atmospheric Administration with Permit Number TUNA-SRP-14-02) carried out from 28 April to 20 May 2014 aboard the R/V F.G.

Walton Smith. The "BLUEFIN14" cruise (approved by the Spanish Institute of Oceanography (Instituto Español de Oceanografía) "BLUEFIN TUNA" project) explored a total of 123 stations and took place from 13 June to 3 July 2014 in the western MED on board the R/V SOCIB, of the Balearic Islands Coastal Observing and Forecasting System. Both cruises used similar standardized methodologies for field collection of fish larvae as described previously (LaizCarrion et al., 2015). Larvae were either frozen in liquid nitrogen or preserved in 96\% ethanol immediately upon retrieval.

Larvae were identified as ABFT following morphological, meristic and pigmentation characters. Standard length (SL) was measured to the nearest $0.01 \mathrm{~mm}$ using Image $\mathrm{J} 1.44 \mathrm{a}$ (USA National Institute of Health). Developmental stage was determined following Richards (2005). ABFT-positive stations were first determined for each survey (31 stations in the GOM and 63 in the MED), and a subset of stations was selected for genetic analysis from each spawning ground (15 stations in the GOM and 14 in the MED, see Figure 1). 
A total of 112 ABFT larvae spawned contemporarily in the GOM (62 larvae, 30 from eGOM and 32 from wGOM) and MED (50 larvae) were genotyped (Data S1). DNA extraction from ABFT larval tissue was performed with the NucleoSpin ${ }^{\circledR}$ Tissue XS (Macherey-Nagel), and PCR amplification of microsatellite loci alleles was carried out as described in Uriarte et al., (2019) with modifications (Table S1). Guts were removed prior to analysis to avoid interference from potential piscivory or cannibalism as observed by Uriarte et al., (2019) (except for 18 individuals for which low standard length excluded the possibility of piscivory). moderate-to-high allele count and compatible amplification in two multiplex PCR reactions (Table S1). Allele calling after fragment analysis (STABVIDA, Portugal) was performed with GeneMapper® software v4.0 (Applied Biosystems) by two independent readers. We used

170 GeneScan ${ }^{\mathrm{TM}} 500 \mathrm{LIZ}{ }^{\circledR}$ (Applied Biosystems) as size standard. The internal threshold for missing data per individual was $25 \%$ (six genotyped loci), which allows for an overall maximum missing data of $13 \%$ for locus Tth16-2. A fragment of $\sim 450 \mathrm{bp}$ of the mitochondrial control region

173 (Viñas \& Tudela, 2009), was sequenced in a subset of genotyped larvae (22 from GOM and 21 from MED). Partial mtDNA control region sequences were assigned to $T$. thynnus based on 175 sequence similarity searches performed with the nucleotide Basic Local Alignment Search Tool (BLAST) (https://blast.ncbi.nlm.nih.gov/). Quality trimmed sequences left a fragment of $361 \mathrm{bp}$ aligned detecting 53 haploid binary sites with SNPs. All sequences have been submitted to GenBank (accession numbers MT912036-MT912078). 

GenAlEx software v6.5 (Peakall \& Smouse, 2012) to assess diversity through observed $\left(\mathrm{H}_{\mathrm{O}}\right)$ and expected $\left(\mathrm{H}_{\mathrm{E}}\right)$ heterozygosity. Software Cervus v3.0.7 (Kalinowski, Taper \& Marshall, 2007) was used to calculate the polymorphic information content (PIC) and to obtain null allele frequencies using the Maximum Likelihood estimator of Summer and Amos (1997). MICROCHECKER (Van Oosterhout et al., 2004) was used to further assess null alleles and genotyping errors. GENEPOP 4.7 (Raymond \& Rousset, 1995; Rousset, 2008) was used to calculate the inbreeding coefficient $\mathrm{F}_{\text {IS }}$ (Weir \& Cockerham, 1984) and compliance to equilibrium of HardyWeinberg (HW). We followed Weir (1996) correcting probability values due to low counts for certain genotypes with the Markov Chain Monte Carlo (MCMC) approximation (involving 10,000 dememorization steps, 1000 batches and 10,000 iterations per batch). The presence of full siblings was screened through replicate sibship analyses with multilocus genotypes excluding individuals with missing data. Analyses were run with COLONY (Wang, 2004; Jones \& Wang, 2010), assuming an inbreeding polygamous model, performing ten very long runs to assess maximum likelihood sibship. Genotype accumulation curves were explored in $R$ free software (R Team, 2018) in RStudio (RStudio Team, 2019) with the "poppr" package (Kamvar, Tabima \&

Grünwald, 2014). assess partitioning of genetic diversity at microsatellite loci and at the mtDNA control region within subpopulations relative to the total population. The Wright's F statistic $\mathrm{F}_{\mathrm{ST}}$, G" ${ }_{\mathrm{ST}}$

201 (Hedrick's standardized $\mathrm{G}_{\mathrm{ST}}$ further corrected for bias for small $k$ populations) (Meirmans \& 202 Hedrick, 2011), and Jost's D estimate of differentiation (Jost, 2008) were calculated, and the 
203

204

205

206

207

208

209

210

211

212

213

214

215

216

217

218

219

220

221

associated probability (p) was obtained based on a 999 data permutation test. For ABFT mtDNA haplotypes the $\mathrm{F}_{\mathrm{ST}}$ analogous Phi $\mathrm{PT}_{\mathrm{PT}}$ was obtained through Analysis of Molecular Variance (AMOVA) of genetic distances. Spatial genetic analysis of both nuclear and mitochondrial diversity was studied performing a Mantel test with GenAlEx software v6.5 (Peakall \& Smouse, 2012). Mantel correlation coefficient $R x y$ for matrix and spatial autocorrelation within distance classes were performed calculating $\mathrm{r}$ by bootstrapping.

Two approaches, Bayesian algorithms and Discriminant Analysis of Principal Components (DAPC), proportionally assigned individuals to population clusters inferred from the microsatellite genetic data. In the Bayesian approach, STRUCTURE v2.3.4 software (Pritchard, Stephens \& Donnelly, 2000) was used to analyze ABFT larvae genotyped at six microsatellite loci assuming an ancestry admixture correlated allele frequency model (Falush, Stephens \& Pritchard, 2003), and considering prior sampling location information. Running parameters were set to a burn-in of $2.5 \times 10^{4}$ followed by a MCMC simulation of $5 \times 10^{4}$ runs simulating $K 1$ to 3 populations in 25 iterations. STRUCTURE results were explored with Structure Harvester (Earl \& vonHoldt, 2012). Clumpak (Kopelman et al., 2015) was used to detect the consensus solutions for two $K$ clusters that best fit the Bayesian algorithm used by STRUCTURE. In the DAPC approach we used the R package adegenet (Jombart, 2008) to study differences among clusters identified from ABFT larvae genotyped at six microsatellite loci, and also from polymorphisms in mtDNA. 


\section{Results}

223

224

225

226

227

228

229

230

231

232

233

234

235

236

237

238

239

240

241

242

243
Field collection and genetic characterization of ABFT larvae

During the 2014 spawning season, approximately half of the stations explored were positive for ABFT larvae (Fig. 1), 43\% for GOM and 55\% for MED. We genetically

characterized a total of 112 ABFT larvae spawned contemporarily in the GOM (62 larvae) and MED (50 larvae), excluding overlap in generations. In the GOM, two sample subsets were separated east (30 larvae) and west (32 larvae) of $90^{\circ} \mathrm{W}$ according to oceanographic features known to influence ABFT catches (Teo \& Block, 2010; Muller-Karger et al., 2015), with the eGOM dominated by the Loop Current shedding large anti-cyclonic eddies, which generate mesoscale cyclonic and anti-cyclonic eddies that are the key features of the wGOM, preferred by breeding ABFT, and influencing larval fish distribution (Lindo-Atichati et al., 2012). Mean SL and standard deviation in mm were $4.94 \pm 1.05(\mathrm{MED})$ and $4.55 \pm 0.64(\mathrm{GOM})($ wGOM $4.49 \pm$ 0.49 and eGOM $4.62 \pm 0.77)$.

The mean number of larvae genotyped at eight microsatellite loci are shown in Table S2, for each of the two spawning areas (GOM and MED), or for the three separate geographical regions (wGOM, eGOM and MED again). The number of individuals was sufficient to adequately quantify allele frequencies (Hale, Burg \& Steeves, 2012) and further analyze diversity through heterozygosity. The overall number of alleles ranged from six for locus Tth157 to 25 for locus Tth208 (see Table S2), with the highest polymorphic information content (PIC) score (PIC 0.9) obtained for loci Tth208 and Tth1-31. Scoring errors due to stuttering or large allele dropout were excluded with MICRO-CHECKER (Van Oosterhout et al., 2004), whereas null alleles may be present at loci Tthol and Tth16-2 according to homozygote excess and null

Peer] reviewing PDF | (2020:08:52112:2:0:NEW 13 May 2021) 
244 allele frequency (Table S2). Deviations from expected proportions in large populations in HW

245 equilibrium imply non-random mating, selection for certain genotypes, mutations, or small

246 population sizes. Under the assumptions of $\mathrm{HW}$ equilibrium, the inbreeding coefficient $\left(\mathrm{F}_{\mathrm{IS}}\right)$

247 varies between -1 and +1 , measuring the difference between expected heterozygosity $\left(\mathrm{H}_{\mathrm{E}}\right)$ and

248 observed heterozygosity $\left(\mathrm{H}_{\mathrm{O}}\right)$ according to allele frequencies. Significant deviations from $\mathrm{HW}$

249 proportions and homozygote excess (positive $\mathrm{F}_{\text {IS }}$ ) were obtained for loci Tth16-2 and Ttho1

250 (Table 1), as expected from their null allele frequencies (Table S2). Locus Tth16-2 is the

251 microsatellite that deviated most from HW proportions in all populations and areas (Table 1).

252 Close to zero $\mathrm{F}_{\mathrm{IS}}$ and low null allele frequency did not explain deviation from proportions

253 expected in HW equilibrium for loci Tth157 and Ttho7 in the GOM dataset (Table 1).

Characterization of genetic diversity in larval ABFT may be biased if closely related individuals are collected during plankton sampling. The full-likelihood method implemented in COLONY (Wang, 2004; Jones \& Wang, 2010) can perform sibship analysis to detect full siblings, and is better than other software for parentage analysis in natural populations (Harrison et al., 2013). In both spawning areas, sibship was inferred from $\sim 50$ replicate multilocus genotype datasets and the resulting parameters averaged (Table S3). The hypothesized numbers of families were high and very similar between spawning areas, $45 \pm 4$ in the GOM and $47 \pm 1$ in the MED, supporting unbiased characterization of genetic diversity. Spatial structuring of ABFT genetic diversity Structuring of genetic diversity between ABFT spawning areas was assessed from multilocus genotypes considering all genotyped microsatellite loci or excluding those with null alleles (Tth16-2 and Ttho1). Partitioning of the total expected genetic diversity between 
266 subpopulations or groups under the assumption of equilibrium was quantified through several

267 statistics ranging from 0 to +1 . We calculated the general or most frequently used fixation index

$268 \mathrm{~F}_{\mathrm{ST}}$, originally established by Wright for two allele systems, and we also obtained Hedrick's

269 standardized G" ${ }_{\text {ST }}$ (Meirmans \& Hedrick, 2011) and Jost's D estimate of differentiation (Jost,

270 2008), which are standardized relative to marker heterozygosity and are thus more appropriate

271 estimators for highly polymorphic microsatellite loci. When we only consider genotypes at six

272 microsatellite loci, excluding the two loci with null alleles, genetic differentiation is captured by

273 the value of $\mathrm{G}_{\mathrm{ST}}$ and D. Close to zero values with significant associated probabilities for

274 deviation of homogeneity or equilibrium were obtained for GOM versus MED comparisons

275 (Table 2). Genetic diversity partitioning between MED and the two subregions wGOM and

276 eGOM, resulted in higher estimator values and levels of significance for MED versus the

277 wGOM, in support of greater connectivity between ABFT breeding in the MED and in the

278 eGOM during 2014. Pairwise comparisons of wGOM and eGOM genotypes supported genetic

279 homogeneity, with non-significant probabilities associated with close to zero statistics $F_{\mathrm{ST}}$, $\mathrm{G}_{\text {ST }}$

280 and D, excluding structuring of genetic diversity within the GOM spawning area.

Unique individuals were completely discriminated with four loci according to a genotype accumulation curve (Fig. S1). We obtained diversity estimators from ABFT larvae genotypes at the four most informative loci (PIC $\geq 0.7$ ) that were neutral or in accordance with $\mathrm{HW}$

284 proportions, thus informing of homogeneity of diversity between larval groups. Table 2 shows

285 that four neutral microsatellite loci: Tth208, Tth1-31, Ttho4 and Tth34; detected structuring

286 between larvae spawned in breeding grounds of each ABFT stock, underlining the power of 287 resolution of microsatellite loci as markers for this tuna species. Even multilocus genotypes for 
only the two loci with the highest PIC were able to significantly detect structuring between GOM

289 and MED larvae (data not shown).

Pairwise comparison of MED and GOM larvae haplotypes at $53 \mathrm{mtDNA}$ control region variable sites (SNPs) through AMOVA resulted in a PhiPT value of 0.029 (with a significant associated data randomization probability of 0.019 with 999 permutations). Phylogenetic analysis of mtDNA sequences to infer evolutionary relationships from a common ancestor failed to separate larvae spawned in the MED and in the GOM (data not shown), as previously reported

(Alvarado Bremer et al., 2005; Carlsson et al., 2007). in fixation indexes within the ranges reported thus far, analyzing polymorphism in ABFT mtDNA sequences, microsatellite loci or SNPs, in samples of certain (larvae) or almost certain (juveniles) origin (Carlsson et al., 2007; Puncher et al., 2018; Rodríguez-Ezpeleta et al., 2019) (Table 3). We collected ABFT larvae in a precise spatial and temporal frame, and our results are consistent with other genetically characterized juvenile ABFT and larvae collected in different years and areas compiled in Table 3 . Besides $\mathrm{F}_{\mathrm{ST}}$, we report other genetic diversity estimators, $\mathrm{G}_{\text {ST }}$ (Hedrick's standardized $\mathrm{G}_{\mathrm{ST}}$ further corrected for bias for small $k$ populations) and D (Jost's estimate of differentiation), as they show a higher variance (Meirmans \& Hedrick, 2011), and are complementary measures of fixation and allelic differentiation (Bird et al., 2011; Jost et al., 2018), arguing against the generalized exclusive use of $\mathrm{F}_{\mathrm{ST}}$. the same spawning area than when comparing larvae from different spawning areas. Spatial genetic analyses were performed by analyzing the autocorrelation between geographic and 
310 genetic data through a Mantel test. Close to zero autocorrelation statistics resulted from

311 analyzing genotypes for six loci (R $0.127, \mathrm{p} 0.001)$ and mtDNA control region binary haplotypes

312 (R 0.051, p 0.022). Genetic structuring within different distance classes (within the same or

313 different spawning areas) was explored through multivariate spatial autocorrelation analysis.

314 Autocorrelation for microsatellite genotypes resulted in a positive $r$ value of 0.024 (with

315 confidence limits of 0.005 and -0.004 ) for distance classes within the same spawning area and a

316 negative $r$ value of -0.020 (with $U$ of 0.003 and $L$ of -0.004 ) for distance classes belonging to

317 different spawning areas, in agreement with a weak but significant spatial structuring of genetic 318 diversity.

We investigated connectivity and structuring of genetic diversity through assignment of individual ABFT larvae to two $K$ clusters through a Bayesian analysis of multilocus genotypes in an admixture model considering prior location information (Fig. 2A-C). In two out of three consensus solutions, representing $32 \%$ of all simulations, a gradient from wGOM to MED was observed in the proportion of assignment of each larva to two clusters, with eGOM appearing as an intermediate or mixing area (Fig. 2B and 2C). Figure S2 shows the statistic $\Delta K$ (deltaK)

325 proposed by Evanno, Regnaut \& Goudet, (2005) to detect the real number of clusters based on 326 the rate of change of probabilities between successive $K$ values, and that for our data is necessarily only obtained for $K=2$. A different clustering approach is multivariate DAPC analysis that is applied to discriminate clusters through discriminant analysis performed on data previously transformed through principal components analysis (Jombart, Devillard \& Balloux, 2010). Assignment of individual ABFT larvae to clusters performing DAPC with one discriminant function (DF) clearly separated larvae spawned in the GOM and in the MED (Fig. 2D). DAPC analysis of variable sites found in the mtDNA control region sequences also 
333 separated larvae spawned at Eastern and Western stock reproduction areas (Fig. S3). In Figure

$3342 \mathrm{D}$, the similar proportion of assigned individuals to the wGOM and the eGOM supports absence

335 of structuring within the GOM spawning area. Retaining 0.925 variance in two DFs separated

336 ABFT spawned in wGOM, eGOM and MED in three overlapping clusters (Fig. 2E).DAPC is

337 thus in accordance with the wGOM to MED gradient observed through Bayesian clustering, and

338 supports apparent connectivity between the ABFT Western and Eastern stocks. Separate density

339 plots (Fig. 2F and 2G) for DF1 (eigen value 64.72) and DF2 (eigen value 29.34) also illustrate

340 homogeneity between larvae spawned in the GOM. 


\section{Discussion}

This initial study analyzes ABFT genetic structure exclusively through larvae spawned

343 contemporarily in the GOM and in the MED, and to our knowledge structuring within the ABFT

344 GOM spawning grounds is hereby investigated for the first time. In accordance to previous

345 studies summarized in Table 3, we conclude that there is weak genetic structuring between

346 ABFT stocks through nuclear microsatellites and mitochondrial sequences, which excludes

347 philopatric dispersal of ABFT, as no differences were found between markers inherited

348 biparentally (microsatellites) or through the breeding females (mtDNA). In contrast, in other

349 highly migratory marine species, sex-biased gene flow does result in complex population

350 structure. This is the case of the loggerhead turtle, a species in which population structuring is

351 detected to increase with life stages according to maternally inherited mtDNA, as opposed to

352 absence of differentiation in microsatellite loci due to the constant gene flow driven by the males

353 during migration (Bowen et al., 2005). For the case of highly migratory tuna populations with

354 high levels of gene flow, this study supports the use of larvae and microsatellites for population

355 genetics, detecting weak structuring between larvae spawned in the main breeding grounds of

356 large sized and highly mixed populations with only four neutral loci. The use of microsatellites

357 in population genetics has diminished due to the emergence of high throughput sequencing

358 technologies (Ovenden et al., 2015; Cuéllar-Pinzón et al., 2016), with certain studies reporting

359 that 4-12 SNPs are equivalent to one microsatellite locus (Guichoux et al., 2011). Two studies

360 have analyzed SNPs in ABFT collections detecting weak structuring between management units

361 with as few as 36 SNPs (Rodríguez-Ezpeleta et al., 2019) or 24 SNPs (Puncher et al., 2018), with

$362 \mathrm{~F}_{\mathrm{ST}}$ obtained from GOM-MED comparisons ranging from 0.004 to 0.034 , respectively. Antoniou

363 et al. (2017) characterized ABFT adult samples collected in the MED through genome-wide 
364 SNPs and 16 microsatellite loci, but only found statistically significant close to zero $\mathrm{F}_{\mathrm{ST}}$ values

365 for microsatellite multilocus genotypes. Studies addressing identification of microsatellites in

366 ABFT are scarce with some of the loci selected for the present study assessed in different ABFT

367 collections (Carlsson et al., 2004, 2007; Riccioni et al., 2010, 2013; Vella et al., 2016; Antoniou

368 et al., 2017). For future monitoring of ABFT population dynamics genetic tools ought to be

369 standardized.

The use of early life stages for population genetics in highly migratory species such as

ABFT, that lack barriers to gene flow, is important as it provides the genetic signal from

372 successful breeders. Sibship analysis did not reveal impartiality in sampling related individuals when collecting larvae in GOM or MED spawning areas, which is consistent with previous studies reporting highly unrelated collections of ABFT larvae and juveniles (Puncher et al., 2018). The larvae analyzed in this study belonged to a single generation and were theoretically drawn from single and randomly mating units with cluster analysis supporting detectable connectivity between eGOM and MED spawning areas. Our separation of wGOM and eGOM data to assess HW equilibrium was artificial and no structuring between GOM subregions was found. However, proportions expected in HW for loci Ttho7 and Tth157, with increased significant deviation for pooled data, could be interpreted as a recent sign of non-random mating between reproducing adults within the GOM. A hypothetical resident population of breeding ABFT in the wGOM would agree with increased gene flow between stocks in the eGOM, as suggested by pairwise genetic diversity estimators corrected for multiple comparisons. Bearing in mind we did not find structuring within the GOM, the fact that clustering presents the eGOM as an intermediate overlapping area between MED and wGOM also supports the existence of mixing areas for breeders from each stock, which we propose would occur in the eGOM. A 
387 scenario with ABFT adults migrating from the MED or the eastern northern Atlantic Ocean to

388 spawn in the eGOM would be plausible considering their larger population size and the observed

389 spatial patterns demonstrating transoceanic migrations, in addition to the similar trophic

390 baselines reported for the eGOM and MED environments (Laiz-Carrion et al., 2015).

Conservation and management of ABFT demand continuous research into connectivity

between Western and Eastern ABFT stocks, with variable rates of movement and population

exchange in mixing hotspots in the North Atlantic Ocean (Rooker et al., 2019), and discrepancy

between environmental and genetic profiles reported recently for some adults (Brophy et al., 2020). Several studies have in fact shown there is more movement from the Eastern to the

Western stock than vice versa (Block et al., 2005; Rooker et al., 2008b; Taylor et al., 2011), and reproductive mixing between stocks is proposed to occur in the Slope Sea (Richardson et al., 2016). Puncher et al. (2018) and Rodríguez-Ezpeleta et al. (2019) evaluated the assignment power of their respective traceability SNP panels that were specifically selected based on their capacity to differentiate stocks analyzing YOY and larvae (in lower or similar numbers to this study, see Table 3). In agreement with our results indicating connectivity between eGOM and MED, they found incorrect assignment for certain individuals of known natal origin. Puncher et al. (2018) found the proportion of larvae and YOY juveniles poorly assigned was higher in the western Atlantic Ocean compared to the MED. Rodríguez-Ezpeleta et al. (2019) found higher percentage of incorrect assignment for GOM (10\%) than for MED (2\%); and more intriguingly, assigned larvae from the Slope Sea to both management areas, which could be in agreement with interbreeding of GOM and MED tuna in that region, and according to our results this hypothetical scenario would extend to the eGOM. In summary, genetic tools are able to detect weak ABFT population structuring by analyzing biological material obtained from larval stages, 
410 indicating apparent connectivity between GOM and MED spawning grounds, and calling for

411 future research into areas favorable for mixing of breeders of separate management units to 412 ensure conservation of genetic diversity. 


\section{Conclusions}

415 A cooperative effort allowed collection of tuna larvae during the 2014 reproductive 416 season in the GOM and the MED, the main spawning areas for the Western and the Eastern 417 ABFT stocks correspondingly. Genetic diversity was characterized for the first time exclusively 418 from larval individuals of known origin that provide the signal of successful breeders. Significant 419 genetic structuring between larvae spawned in each spawning ground was found, in agreement 420 with previous studies. Segregation of ABFT larval individuals within the GOM according to 421 oceanographically distinct features in eGOM and wGOM does not indicate structuring. Fixation 422 indices and clustering analysis indicated weak but detectable connectivity between ABFT that

423 breed in the MED and in the eGOM was stronger than between adults spawning in the MED and 424 the wGOM, calling for future research into areas favorable for mixing of breeders belonging to 425 different stocks. 


\section{Acknowledgements}

428 We appreciate the sampling efforts conducted at sea on R/V F.G. Walton Smith and

429 SOCIB. We are grateful for larval collection, processing and analyses to the laboratories of the

430 NOAA Southeast Fisheries Science Center and the Spanish Institute of Oceanography (Instituto

431 Español de Oceanografía), we thank Amaya Uriarte for sample processing. Valuable comments

432 were provided by Sarah Privoznik. The scientific results and conclusions, as well as any views or

433 opinions expressed herein, are those of the author(s) and do not necessarily reflect those of

434 NOAA or the Department of Commerce.

435

436

437 
439

440

441

442

443

444

445

446

447

448

449

450

451

452

453

454

455

456

457

458

459

460

461

462

463

464

465

466

467

468

469

470

471

472

473

474

475

\section{References}

Abdul-Muneer PM. 2014. Application of Microsatellite Markers in Conservation Genetics and Fisheries Management: Recent Advances in Population Structure Analysis and Conservation Strategies. Genetics Research International 2014:1-11. DOI: $10.1155 / 2014 / 691759$.

Alvarado Bremer JR, Viñas J, Mejuto J, Ely B, Pla C. 2005. Comparative phylogeography of Atlantic bluefin tuna and swordfish: The combined effects of vicariance, secondary contact, introgression, and population expansion on the regional phylogenies of two highly migratory pelagic fishes. Molecular Phylogenetics and Evolution 36:169-187. DOI: 10.1016/j.ympev.2004.12.011.

Antoniou A, Kasapidis P, Kotoulas G, Mylonas CC, Magoulas A. 2017. Genetic diversity of Atlantic Bluefin tuna in the Mediterranean Sea: Insights from genome-wide SNPs and microsatellites. Journal of Biological Research (Greece) 24:1-14. DOI: 10.1186/s40709017-0062-2.

Bird CE, Karl SA, Mouse PE, Toonen RJ. 2011. Detecting and measuring genetic differentiation. In: Phylogeography and Population Genetics in Crustacea. 19:31-55. DOI: 10.1201/b11113-4.

Block BA, Teo SLH, Walli A, Boustany A, Stokesbury MJW, Farwell CJ, Weng KC, Dewar H, Williams TD. 2005. Electronic tagging and population structure of Atlantic bluefin tuna. Nature 434:1121-1127. DOI: 10.1038/nature03463.

Boustany AM, Reeb CA, Block BA. 2008. Mitochondrial DNA and electronic tracking reveal population structure of Atlantic bluefin tuna (Thunnus thynnus). Marine Biology 156:13-24. DOI: $10.1007 / \mathrm{s} 00227-008-1058-0$.

Bowen BW, Bass AL, Soares L, Toonen RJ. 2005. Conservation implications of complex population structure: Lessons from the loggerhead turtle (Caretta caretta). Molecular Ecology 14:2389-2402. DOI: 10.1111/j.1365-294X.2005.02598.x.

Brophy D, Rodríguez-Ezpeleta N, Fraile I, Arrizabalaga H. 2020. Combining genetic markers with stable isotopes in otoliths reveals complexity in the stock structure of Atlantic bluefin tuna (Thunnus thynnus). Scientific Reports 10:1-17. DOI: 10.1038/s41598-020-71355-6.

Carlsson J, McDowell JR, Carlsson JEL, Graves JE. 2007. Genetic identity of YOY bluefin tuna from the eastern and western Atlantic spawning areas. Journal of Heredity 98:23-28. DOI: $10.1093 /$ jhered/es1046.

Carlsson J, McDowell JR, Díaz-Jaimes P, Carlsson JEL, Boles SB, Gold JR, Graves JE. 2004. Microsatellite and mitochondrial DNA analyses of Atlantic bluefin tuna (Thunnus thynnus thynnus) population structure in the Mediterranean Sea. Molecular Ecology 13:3345-3356. DOI: 10.1111/j.1365-294X.2004.02336.x.

Cuéllar-Pinzón J, Presa P, Hawkins SJ, Pita A. 2016. Genetic markers in marine fisheries: Types, 
476

477

478

479

480

481

482

483

484

485

486

487

488

489

490

491

492

493

494

495

496

497

498

499

500

501

502

503

504

505

506

507

508

509

510

511

tasks and trends. Fisheries Research 173:194-205. DOI: 10.1016/j.fishres.2015.10.019.

Earl DA, vonHoldt BM. 2012. STRUCTURE HARVESTER: A website and program for visualizing STRUCTURE output and implementing the Evanno method. Conservation Genetics Resources 4:359-361. DOI: 10.1007/s12686-011-9548-7.

Evanno G, Regnaut S, Goudet J. 2005. Detecting the number of clusters of individuals using the software STRUCTURE: A simulation study. Molecular Ecology 14:2611-2620. DOI: 10.1111/j.1365-294X.2005.02553.x.

Falush D, Stephens M, Pritchard JK. 2003. Inference of population structure using multilocus genotype data: Linked loci and correlated allele frequencies. Genetics 164:1567-1587. DOI: 10.1080/13235818.1996.10673675.

Goldberg CS, Waits LP. 2010. Quantification and reduction of bias from sampling larvae to infer population and landscape genetic structure. Molecular Ecology Resources 10:304-313. DOI: $10.1111 / \mathrm{j} .1755-0998.2009 .02755 . x$.

Guichoux E, Lagache L, Wagner S, Chaumeil P, Léger P, Lepais O, Lepoittevin C, Malausa T, Revardel E, Salin F, Petit RJ. 2011. Current trends in microsatellite genotyping. Molecular Ecology Resources. DOI: 10.1111/j.1755-0998.2011.03014.x.

Hale ML, Burg TM, Steeves TE. 2012. Sampling for Microsatellite-Based Population Genetic Studies: 25 to 30 Individuals per Population Is Enough to Accurately Estimate Allele Frequencies. PLoS ONE 7. DOI: 10.1371/journal.pone.0045170.

Harrison HB, Saenz-Agudelo P, Planes S, Jones GP, Berumen ML. 2013. Relative accuracy of three common methods of parentage analysis in natural populations. Molecular Ecology 22:1158-1170. DOI: $10.1111 / \mathrm{mec} .12138$.

ICCAT. 2020. ICCAT Report for biennial period, 2018-19 PART II (2019).

Ingram GW, Alvarez-Berastegui D, Reglero P, Balbín R, García A, Alemany F. 2017. Incorporation of habitat information in the development of indices of larval bluefin tuna (Thunnus thynnus) in the Western Mediterranean Sea (2001-2005 and 2012-2013). DeepSea Research Part II: Topical Studies in Oceanography. DOI: 10.1016/j.dsr2.2017.03.012.

IUCN. 2020.The IUCN Red List of Threatened Species.

Jombart T. 2008. Adegenet: A R package for the multivariate analysis of genetic markers. Bioinformatics 24:1403-1405. DOI: 10.1093/bioinformatics/btn129.

Jombart T, Devillard S, Balloux F. 2010. Discriminant analysis of principal components: A new method for the analysis of genetically structured populations. BMC Genetics 11:94. DOI: 10.1186/1471-2156-11-94.

Jones OR, Wang J. 2010. COLONY: A program for parentage and sibship inference from multilocus genotype data. Molecular Ecology Resources 10:551-555. DOI: 10.1111/j.17550998.2009.02787.x. 
512

513

514

515

516

517

518

519

520

521

522

523

524

525

526

527

528

529

530

531

532

533

534

535

536

537

538

539

540

541

542

543

544

545

546

547

548

549

Jost L. 2008. GST and its relatives do not measure differentiation. Molecular Ecology 17:40154026. DOI: 10.1111/j.1365-294X.2008.03887.x.

Jost L, Archer F, Flanagan S, Gaggiotti O, Hoban S, Latch E. 2018. Differentiation measures for conservation genetics. Evolutionary Applications 11:1139-1148. DOI: 10.1111/eva.12590.

Kalinowski ST, Taper ML, Marshall TC. 2007. Revising how the computer program CERVUS accommodates genotyping error increases success in paternity assignment. Molecular Ecology. DOI: 10.1111/j.1365-294X.2007.03089.x.

Kamvar ZN, Tabima JF, Grüunwald NJ. 2014. Poppr: An R package for genetic analysis of populations with clonal, partially clonal, and/or sexual reproduction. PeerJ. DOI: $10.7717 /$ peerj. 281 .

Kopelman NM, Mayzel J, Jakobsson M, Rosenberg NA, Mayrose I. 2015. Clumpak: A program for identifying clustering modes and packaging population structure inferences across $\mathrm{K}$. Molecular Ecology Resources 15:1179-1191. DOI: 10.1111/1755-0998.12387.

Kumar G, Kocour M. 2015. Population genetic structure of tunas inferred from molecular markers: A review. Reviews in Fisheries Science and Aquaculture 23:72-89. DOI: 10.1080/23308249.2015.1024826.

Laiz-Carrión R, Gerard T, Suca JJ, Malca E, Uriarte A, Quintanilla JM, Privoznik S, Llopiz JK, Lamkin J, García A. 2019. Stable isotope analysis indicates resource partitioning and trophic niche overlap in larvae of four tuna species in the Gulf of Mexico. Marine Ecology Progress Series 619:53-68. DOI: 10.3354/meps 12958.

Laiz-Carrion R, Gerard T, Uriarte A, Malca E, Quintanilla JM, Muhling BA, Alemany F, Privoznik SL, Shiroza A, Lamkin JT, Garcia A. 2015. Trophic ecology of Atlantic bluefin tuna (Thunnus thynnus) larvae from the Gulf of Mexico and NW Mediterranean spawning grounds: A comparative stable isotope study. PLoS ONE 10. DOI: 10.1371/journal.pone.0133406.

Lindo-Atichati D, Bringas F, Goni G, Muhling B, Muller-Karger FE, Habtes S. 2012. Varying mesoscale structures influence larval fish distribution in the northern Gulf of Mexico. Marine Ecology Progress Series. DOI: 10.3354/meps09860.

Malca E, Muhling B, Franks J, García A, Tilley J, Gerard T, Ingram W, Lamkin JT. 2017. The first larval age and growth curve for bluefin tuna (Thunnus thynnus) from the Gulf of Mexico: Comparisons to the Straits of Florida, and the Balearic Sea (Mediterranean). Fisheries Research 190:24-33. DOI: 10.1016/j.fishres.2017.01.019.

Meirmans PG, Hedrick PW. 2011. Assessing population structure: FST and related measures. Molecular Ecology Resources. DOI: 10.1111/j.1755-0998.2010.02927.x.

Muhling BA, Lamkin JT, Alemany F, García A, Farley J, Ingram GW, Berastegui DA, Reglero P, Carrion RL. 2017. Reproduction and larval biology in tunas, and the importance of restricted area spawning grounds. Reviews in Fish Biology and Fisheries 27:697-732. DOI: 10.1007/s11160-017-9471-4. 
Muller-Karger FE, Smith JP, Werner S, Chen R, Roffer M, Liu Y, Muhling B, Lindo-Atichati D, Lamkin J, Cerdeira-Estrada S, Enfield DB. 2015. Natural variability of surface oceanographic conditions in the offshore Gulf of Mexico. Progress in Oceanography. DOI: 10.1016/j.pocean.2014.12.007.

Van Oosterhout C, Hutchinson WF, Wills DPM, Shipley P. 2004. MICRO-CHECKER: Software for identifying and correcting genotyping errors in microsatellite data. Molecular Ecology Notes. DOI: 10.1111/j.1471-8286.2004.00684.x.

Ovenden JR, Berry O, Welch DJ, Buckworth RC, Dichmont CM. 2015. Ocean's eleven: A critical evaluation of the role of population, evolutionary and molecular genetics in the management of wild fisheries. Fish and Fisheries 16:125-159. DOI: 10.1111/faf.12052.

Peakall R, Smouse PE. 2012. GenALEx 6.5: Genetic analysis in Excel. Population genetic software for teaching and research-an update. Bioinformatics 28:2537-2539. DOI: 10.1093/bioinformatics/bts460.

Pritchard JK, Stephens M, Donnelly P. 2000. Inference of population structure using multilocus genotype data. Genetics 155:945-959.

Puncher GN, Cariani A, Maes GE, Van Houdt J, Herten K, Cannas R, Rodriguez-Ezpeleta N, Albaina A, Estonba A, Lutcavage M, Hanke A, Rooker J, Franks JS, Quattro JM, Basilone G, Fraile I, Laconcha U, Goñi N, Kimoto A, Macías D, Alemany F, Deguara S, Zgozi SW, Garibaldi F, Oray IK, Karakulak FS, Abid N, Santos MN, Addis P, Arrizabalaga H, Tinti F. 2018. Spatial dynamics and mixing of bluefin tuna in the Atlantic Ocean and Mediterranean Sea revealed using next-generation sequencing. Molecular Ecology Resources 18:620-638. DOI: $10.1111 / 1755-0998.12764$.

R Team. 2018. A Language and Environment for Statistical Computing. R Foundation for Statistical Computing 2:https://www.R-project.org.

Raymond M, Rousset F. 1995. GENEPOP (Version 1.2): Population Genetics Software for Exact Tests and Ecumenicism. Journal of Heredity. DOI: 10.1093/oxfordjournals.jhered.a111573.

Riccioni G, Landi M, Ferrara G, Milano I, Cariani A, Zane L, Sella M, Barbujani G, Tinti F. 2010. Spatio-temporal population structuring and genetic diversity retention in depleted Atlantic Bluefin tuna of the Mediterranean Sea. Proceedings of the National Academy of Sciences of the United States of America 107:2102-2107. DOI: 10.1073/pnas.0908281107.

Riccioni G, Stagioni M, Landi M, Ferrara G, Barbujani G, Tinti F. 2013. Genetic structure of bluefin tuna in the mediterranean sea correlates with environmental variables. PLoS ONE 8. DOI: 10.1371/journal.pone.0080105.

Richards WJ. 2005. Early stages of Atlantic fishes. In: CRC T and FGLL. ed. An Identification Guide forthe Western Central North Atlantic. 2591.

Richardson DE, Marancik KE, Guyon JR, Lutcavage ME, Galuardi B, Lam CH, Walsh HJ, Wildes S, Yates DA, Hare JA. 2016. Discovery of a spawning ground reveals diverse migration strategies in Atlantic bluefin tuna (Thunnus thynnus). Proceedings of the National 
Academy of Sciences of the United States of America 113:3299-3304. DOI: $10.1073 /$ pnas. 1525636113.

Rodríguez-Ezpeleta N, Díaz-Arce N, Walter JF, Richardson DE, Rooker JR, Nøttestad L, Hanke AR, Franks JS, Deguara S, Lauretta M V., Addis P, Varela JL, Fraile I, Goñi N, Abid N, Alemany F, Oray IK, Quattro JM, Sow FN, Itoh T, Karakulak FS, Pascual-Alayón PJ, Santos MN, Tsukahara Y, Lutcavage M, Fromentin JM, Arrizabalaga H. 2019. Determining natal origin for improved management of Atlantic bluefin tuna. Frontiers in Ecology and the Environment 17:439-444. DOI: 10.1002/fee.2090.

Rodriguez JM, Johnstone C, Lozano-Peral D. 2021. Evidence of Atlantic bluefin tuna spawning in the Bay of Biscay, NE Atlantic. Journal of Fish Biology (in press).

Rooker JR, Fraile I, Liu H, Abid N, Dance MA, Itoh T, Kimoto A, Tsukahara Y, RodriguezMarin E, Arrizabalaga H. 2019. Wide-ranging temporal variation in transoceanic movement and population mixing of bluefin tuna in the North Atlantic Ocean. Frontiers in Marine Science 6:1-13. DOI: 10.3389/fmars.2019.00398.

Rooker JR, Secor DH, De Metrio G, Schloesser R, Block BA, Neilson JD. 2008a. Natal homing and connectivity in Atlantic bluefin tuna populations. Science 322:742-744. DOI: 10.1126/science. 1161473 .

Rooker JR, Secor DH, De Metrio G, Schloesser R, Block BA, Neilson JD. 2008b. Atlantic Bluefin Tuna Populations. Science 322:742-744. DOI: 10.1126/science.1161473.

Rooker JR, Secor DH, Zdanowicz VS, De Metrio G, Relini LO. 2003. Identification of Atlantic bluefin tuna (Thunnus thynnus) stocks from putative nurseries using otolith chemistry. Fisheries Oceanography 12:75-84. DOI: 10.1046/j.1365-2419.2003.00223.x.

Rousset F. 2008. GENEPOP'007: A complete re-implementation of the GENEPOP software for Windows and Linux. Molecular Ecology Resources. DOI: 10.1111/j.14718286.2007.01931.x.

RStudio Team. 2019. RStudio: Integrated Development for R. RStudio, Inc., Boston, MA. URL http://www.rstudio.com/. RStudio, Inc.:10.

Taylor NG, McAllister MK, Lawson GL, Carruthers T, Block BA. 2011. Atlantic bluefin tuna: A novel multistock spatial model for assessing population biomass. PLOS ONE 6. DOI: 10.1371/journal.pone.0027693.

Teo SLH, Block BA. 2010. Comparative influence of ocean conditions on yellowfin and Atlantic bluefin tuna catch from longlines in the Gulf of Mexico. PLOS ONE. DOI: 10.1371/journal.pone.0010756.

Uriarte A, Johnstone C, Laiz-Carrión R, García A, Llopiz JK, Shiroza A, Quintanilla JM, Lozano-Peral D, Reglero P, Alemany F. 2019. Evidence of density-dependent cannibalism in the diet of wild Atlantic bluefin tuna larvae (Thunnus thynnus) of the Balearic Sea (NWMediterranean). Fisheries Research. DOI: 10.1016/j.fishres.2018.12.013.

Vella A, Vella N, Karakulak FS, Oray I, Garcia-Tiscar S, de Stephanis R. 2016. Population 
626

genetics of Atlantic bluefin tuna, Thunnus thynnus (Linnaeus, 1758), in the Mediterranean: Implications for its conservation management. Journal of Applied Ichthyology 32:523-531. DOI: $10.1111 /$ jai.13035.

Viñas J, Gordoa A, Fernández-Cebrián R, Pla C, Vahdet Ü, Araguas RM. 2011. Facts and uncertainties about the genetic population structure of Atlantic bluefin tuna (Thunnus thynnus) in the Mediterranean. Implications for fishery management. Reviews in Fish Biology and Fisheries 21:527-541. DOI: 10.1007/s11160-010-9174-6.

Viñas J, Tudela S. 2009. A validated methodology for genetic identification of tuna species (genus Thunnus). PLOS one 4:e7606.

Wang J. 2004. Sibship Reconstruction from Genetic Data with Typing Errors. Genetics. DOI: 10.1534/genetics.166.4.1963.

Weir BS. 1996. Genetic Data Analysis II. By Bruce S. Weir, Sunderland, Massachusetts. Sinauer Associates, Inc.445 pages. ISBN 0-87893-902-4. Genetical Research. DOI: $10.1017 / \mathrm{s} 0016672300034121$.

Weir BS, Cockerham CC. 1984. Estimating F-Statistics for the Analysis of Population Structure. Evolution 38:1358. DOI: 10.2307/2408641. 


\section{Table $\mathbf{1}$ (on next page)}

Table 1. Genetic diversity of Atlantic bluefin tuna (ABFT) larvae genotyped at eight microsatellite loci.

Genetic diversity indicated for each area in which ABFT larvae were collected (Pop), and measured as HO, observed heterozygosity; HE, expected heterozygosity; or FIS inbreeding coefficient calculated according to Weir \& Cockerham (1984). HW indicates probability $p$ value obtained with the exact probability test for Hardy-Weinberg equilibrium calculated by the Markov chain method (10000 dememorization, 1000 batches, 10000 iterations per batch) and level of significance $(* p<0.05, * * p<0.01$ and $* * p<000.1)$. 


\begin{tabular}{|c|c|c|c|c|c|c|c|c|c|c|c|c|c|c|c|c|}
\hline \multirow{3}{*}{$\begin{array}{c}\text { Pop }^{1} \\
\text { Locus }\end{array}$} & \multicolumn{12}{|c|}{ GOM } & \multirow{2}{*}{\multicolumn{4}{|c|}{ MED }} \\
\hline & \multicolumn{4}{|c|}{ wGOM } & \multicolumn{4}{|c|}{ eGOM } & \multicolumn{4}{|c|}{ GOM (wGOM and eGOM) } & & & & \\
\hline & $\mathbf{H}_{\mathbf{O}}$ & $\mathbf{H}_{\mathrm{E}}$ & $F_{\text {IS }}$ & $\mathbf{H W}^{2}$ & $\mathbf{H}_{\mathbf{O}}$ & $\mathbf{H}_{\mathrm{E}}$ & $F_{\text {IS }}$ & HW $^{2}$ & $\mathbf{H}_{\mathbf{O}}$ & $\mathbf{H}_{\mathrm{E}}$ & $F_{\text {IS }}$ & $\mathbf{H W}^{2}$ & $\mathbf{H}_{\mathbf{O}}$ & $\mathbf{H}_{\mathrm{E}}$ & $F_{\text {IS }}$ & $\mathbf{H W}^{2}$ \\
\hline Tth208 & 0.867 & 0.906 & 0.060 & 0.702 & 0.900 & 0.930 & 0.049 & 0.315 & 0.883 & 0.926 & 0.054 & 0.407 & 0.940 & 0.917 & -0.015 & 0.589 \\
\hline Tth1-31 & 0.938 & 0.877 & -0.053 & 0.932 & 0.867 & 0.883 & 0.035 & 0.776 & 0.903 & 0.886 & -0.012 & 0.982 & 0.840 & 0.871 & 0.046 & 0.402 \\
\hline Ttho7 & 0.815 & 0.837 & 0.046 & 0.239 & 0.821 & 0.845 & 0.046 & 0.157 & 0.818 & 0.844 & 0.039 & $0.006^{* *}$ & 0.820 & 0.836 & 0.030 & 0.707 \\
\hline Tth34 & 0.688 & 0.693 & 0.024 & 0.354 & 0.667 & 0.668 & 0.019 & 0.368 & 0.677 & 0.688 & 0.023 & 0.130 & 0.740 & 0.770 & 0.049 & 0.491 \\
\hline Ttho4 & 0.688 & 0.764 & 0.115 & 0.273 & 0.800 & 0.726 & -0.085 & 0.751 & 0.742 & 0.755 & 0.026 & 0.899 & 0.640 & 0.738 & 0.143 & 0.278 \\
\hline Ttho1 & 0.594 & 0.687 & 0.151 & 0.462 & 0.400 & 0.534 & 0.267 & $0.019^{*}$ & 0.500 & 0.625 & 0.208 & $0.025^{*}$ & 0.440 & 0.638 & 0.319 & $0.005^{* *}$ \\
\hline Tth157 & 0.633 & 0.646 & 0.036 & $0.022^{*}$ & 0.433 & 0.457 & 0.068 & 0.077 & 0.533 & 0.562 & 0.059 & $0.004^{* *}$ & 0.660 & 0.594 & -0.102 & 0.943 \\
\hline Tth16-2 & 0.333 & 0.584 & 0.447 & $0.002 * *$ & 0.217 & 0.549 & 0.618 & $0.000 * * *$ & 0.277 & 0.577 & 0.529 & $0.000 * * *$ & 0.280 & 0.523 & 0.472 & $0.000^{* * *}$ \\
\hline
\end{tabular}

${ }^{1}$ Pop refers to each area in which ABFT larvae were collected. ${ }^{2}$ Significance after Bonferroni correction $(\alpha$ 0.05) for multiple comparisons at $\mathrm{p}<$ 30.0016.

4 


\section{Table 2 (on next page)}

Table 2. Pairwise comparison of diversity for indicated spawning areas obtained from ABFT larvae genotypes at indicated number of microsatellite loci.

Genetic diversity estimators FST, G"ST (Hedrick's standardized GST further corrected for bias for small $k$ populations) and Jost's $D$ estimate of differentiation. Associated probability ( $p$ ) indicated in brackets obtained through 999 data permutations and summarized in the last column as non-significant (n.s.) or according to significance levels of $p<0.05\left(^{*}\right)$ and $p<0.01$ $(* *)$. 


\begin{tabular}{|c|c|c|c|c|c|c|c|c|c|c|c|c|}
\hline \multirow[b]{2}{*}{ Genotype $^{1}$} & \multicolumn{3}{|c|}{$\mathbf{F}_{\mathrm{ST}}$} & \multicolumn{3}{|c|}{ G" $_{\text {ST }}$} & \multicolumn{3}{|c|}{ D } & \multicolumn{3}{|c|}{$\mathbf{p}^{2}$} \\
\hline & 8 loci & 6 loci & 4 loci & 8 loci & 6 loci & 4 loci & 8 loci & 6 loci & 4 loci & 8 loci & 6 loci & 4 loci \\
\hline GOM vs MED & $\begin{array}{c}0.009 \\
(0.019)\end{array}$ & $\begin{array}{c}0.010 \\
(0.001)\end{array}$ & $\begin{array}{c}0.011 \\
(0.001)\end{array}$ & $\begin{array}{c}0.029 \\
(0.019)\end{array}$ & $\begin{array}{c}0.047 \\
(0.001)\end{array}$ & $\begin{array}{c}0.070 \\
(0.001)\end{array}$ & $\begin{array}{c}0.021 \\
(0.018)\end{array}$ & $\begin{array}{c}0.037 \\
(0.001)\end{array}$ & $\begin{array}{c}0.059 \\
(0.001)\end{array}$ & * & $\ddot{* *}$ & $* *$ \\
\hline wGOM vs MED & $\begin{array}{c}0.013 \\
(0.012)\end{array}$ & $\begin{array}{c}0.012 \\
(0.005)\end{array}$ & $\begin{array}{c}0.014 \\
(0.003)\end{array}$ & $\begin{array}{c}0.044 \\
(0.014)\end{array}$ & $\begin{array}{c}0.055 \\
(0.005)\end{array}$ & $\begin{array}{c}0.087 \\
(0.003)\end{array}$ & $\begin{array}{c}0.033 \\
(0.012)\end{array}$ & $\begin{array}{c}0.045 \\
(0.005)\end{array}$ & $\begin{array}{c}0.073 \\
(0.003)\end{array}$ & $*$ & $* *$ & $* *$ \\
\hline eGOM vs MED & $\begin{array}{c}0.010 \\
(0.106) \\
\end{array}$ & $\begin{array}{c}0.011 \\
(0.014) \\
\end{array}$ & $\begin{array}{c}0.012 \\
(0.019) \\
\end{array}$ & $\begin{array}{c}0.020 \\
(0.109) \\
\end{array}$ & $\begin{array}{c}0.041 \\
(0.017) \\
\end{array}$ & $\begin{array}{c}0.056 \\
(0.019) \\
\end{array}$ & $\begin{array}{c}0.015 \\
(0.109) \\
\end{array}$ & $\begin{array}{c}0.032 \\
(0.017) \\
\end{array}$ & $\begin{array}{c}0.047 \\
(0.019) \\
\end{array}$ & n.s. & $*$ & $*$ \\
\hline wGOM vs eGOM & $\begin{array}{c}0.011 \\
(0.239)\end{array}$ & $\begin{array}{c}0.009 \\
(0.404)\end{array}$ & $\begin{array}{c}0.009 \\
(0.339)\end{array}$ & $\begin{array}{c}0.013 \\
(0.239)\end{array}$ & $\begin{array}{c}0.004 \\
(0.401)\end{array}$ & $\begin{array}{c}0.008 \\
(0.339)\end{array}$ & $\begin{array}{c}0.009 \\
(0.239)\end{array}$ & $\begin{array}{c}0.003 \\
(0.401)\end{array}$ & $\begin{array}{c}0.006 \\
(0.339)\end{array}$ & n.s. & n.s. & n.s. \\
\hline
\end{tabular}

${ }^{1}$ Data sets including genotypes for eight microsatellite loci (Tth208, Tth1-31, Ttho7, Tth34, Ttho4, Ttho1, Tth157 and Tth16-2), for six loci excluding Tth16-2 and Ttho1 due to null alleles, and at four loci conserving microsatellites in HW equilibrium with higher PIC (Tth208, Tth1-31, Tth34 and Ttho4). ${ }^{2}$ Significance after Bonferroni correction $(\alpha 0.05)$ for multiple comparisons at $\mathrm{p}<0.0042$ is indicated underlined. 


\section{Table 3 (on next page)}

Table 3. Summary of studies assessing ABFT genetic structuring between main spawning areas (GOM and MED) through individuals of early life stages (larvae or young-of-the-year YOY) ensuring correct management unit assignment.

For each study the genetic tool and features of the collection of ABFT individuals used to characterize genetic diversity are summarized. The reported fixation indexes from pairwise comparison between ABFT collected in Western or Eastern stocks is compiled in the last column. 


\begin{tabular}{|c|c|c|c|c|}
\hline \multirow{2}{*}{ Reference } & \multirow{2}{*}{ Genetic Tool } & \multicolumn{2}{|c|}{ ABFT Stock ${ }^{4}$} & \multirow{2}{*}{ Fixation index ${ }^{5}$} \\
\hline & & Western Atlantic & Eastern Atlantic & \\
\hline \multirow{2}{*}{$\begin{array}{l}\text { (Carlsson et al., } \\
\text { 2007). }\end{array}$} & mtDNA sequence ${ }^{1}$ & $\begin{array}{c}\text { Gulf of Mexico (GOM) } \\
\text { Larvae (40) } \\
\text { Year } 2003\end{array}$ & $\begin{array}{l}\text { Mediterranean Sea (MED) } \\
\text { YOY (107) } \\
\text { Years 1998, 1999, 2000, 2001, } \\
2002 .\end{array}$ & $0.013^{*}$ \\
\hline & Microsatellite loci ${ }^{2}$ & $\begin{array}{c}\text { GOM } \\
\text { Larvae }(40) \\
\text { Year 2003 }\end{array}$ & $\begin{array}{c}\text { MED } \\
\text { YOY }(280) \\
\text { Years 1998, 1999, 2000, 2001, } \\
2002 . \\
\end{array}$ & $0.006 * * *$ (8 loci) \\
\hline $\begin{array}{l}\text { (Puncher et al., } \\
\text { 2018). }\end{array}$ & SNP panel ${ }^{3}$ & $\begin{array}{c}\text { GOM (64) and Cape Hatteras (16) } \\
\text { Larvae (64) and YOY (16) } \\
\text { Years 2007, 2008, 2009, 2010. }\end{array}$ & $\begin{array}{c}\text { MED } \\
\text { Larvae (63) and YOY (350) } \\
\text { Years 2008, 2011, 2012, 2013. }\end{array}$ & $\begin{array}{c}0.008 * \text { (95 SNP panel) } \\
0.014 *(58 \text { SNP panel) } \\
0.034 * * \text { (24 SNP panel) }\end{array}$ \\
\hline $\begin{array}{l}\text { (Rodríguez-Ezpeleta } \\
\text { et al., 2019). }\end{array}$ & SNP panel ${ }^{3}$ & $\begin{array}{l}\text { GOM (26) and Slope Sea (13) } \\
\text { Larvae (26) and YOY (13) } \\
\text { Years 2007, 2008, 2009, 2010. }\end{array}$ & $\begin{array}{c}\text { MED } \\
\text { Larvae (48) and YOY (117) } \\
2008,2011,2012,2013 . \\
\end{array}$ & 0.004 (n.i.) \\
\hline \multirow{2}{*}{ This study. } & mtDNA sequence ${ }^{1}$ & $\begin{array}{c}\text { GOM } \\
\text { Larvae (22) } \\
\text { Year 2014 } \\
\end{array}$ & $\begin{array}{c}\text { MED } \\
\text { Larvae (21) } \\
\text { Year 2014 }\end{array}$ & $0.029 *$ \\
\hline & Microsatellite loci ${ }^{2}$ & $\begin{array}{c}\text { GOM } \\
\text { Larvae }(62) \\
\text { Year 2014 }\end{array}$ & $\begin{array}{c}\text { MED } \\
\text { Larvae (50) } \\
\text { Year 2014 }\end{array}$ & $\begin{array}{c}0.009 *(8 \text { loci }) \\
0.010^{* *}(6 \text { loci }) \\
0.011 * * \text { (4 loci })\end{array}$ \\
\hline
\end{tabular}

1

${ }^{1}$ The control region was sequenced in 847 bp (Carlsson et al., 2007) or 361 bp (this study).

${ }^{2}$ Loci Tth5, Tth8, Tth10, Tth21, Tth34, Ttho-1, Ttho-4, and Ttho-7 were genotyped in (Carlsson et al., 2007), and for this study we analyzed loci Tth208, Tth1-31, Ttho7, Tth34, Ttho4, Ttho1, Tth157, and Tth16-2.

${ }^{3}$ SNPs derived from genomewide search for spatially informative loci by restriction site-associated DNA sequencing (RAD-seq).

${ }^{4}$ Phase of early life stage (number of individuals) and collection year.

${ }^{5}$ Significant probability obtained by 999 random permutations $\left({ }^{*} \mathrm{p}<0.05,{ }^{* *} \mathrm{p}<0.01\right.$ and $\left.{ }^{* * *} \mathrm{p}<000.1\right)$, n.i. not indicated. For nuclear markers $\mathrm{F}_{\mathrm{ST}}$ is indicated. For mtDNA Phi $i_{\mathrm{ST}}$ was calculated in (Carlsson et al., 2007), we calculated analogous $\mathrm{Phi}_{\mathrm{PT}}$ for this study. 
Figure 1

Figure 1. Study area and larvae collection.

Atlantic bluefin tuna (ABFT) larvae were collected with plankton nets during 2014 in two main spawning areas for Thunnus thynnus: (A) the Gulf of Mexico (GOM) and (B) the Mediterranean Sea (MED). Explored stations are indicated with crosses, positive stations for ABFT are indicated with empty circles, and filled circles indicate stations where larvae collected were genotyped. In the GOM larvae were collected in two areas, west and east of $90^{\circ} \mathrm{W}$. In the MED larvae were collected in the waters surrounding the Balearic Islands.

A

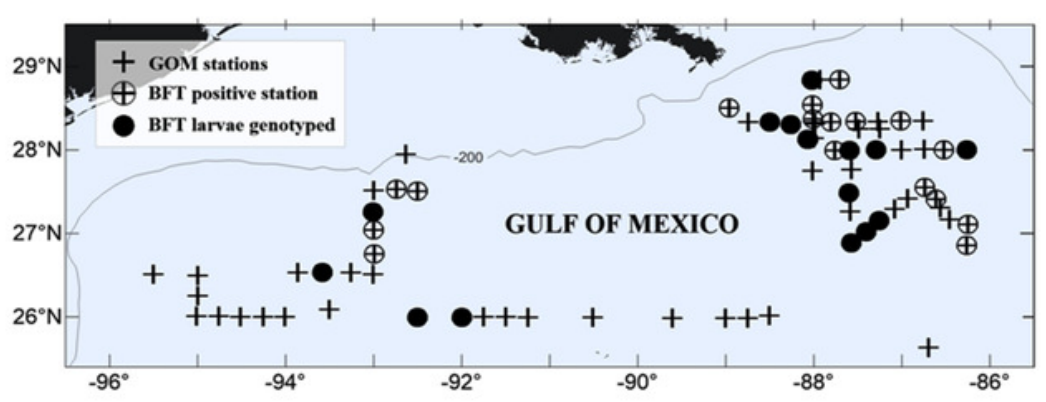

B

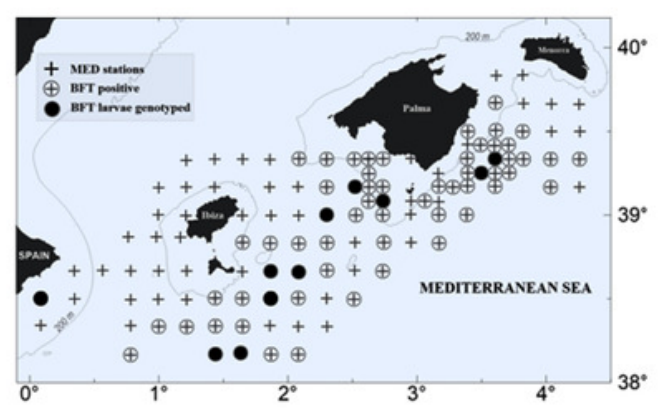




\section{Figure 2}

Figure 2. Clustering of ABFT larvae genetic diversity.

Genotypes at six microsatellite loci (Tth208, Tth1-31, Ttho7, Tth34, Ttho4 and Tth157) were used to characterize genetic diversity of ABFT larvae spawned in the MED (black), and GOM (grey). GOM can be segregated into wGOM (light grey) and eGOM (dark grey). (A-C) Bayesian clustering of ABFT larvae performed with STRUCTURE V2.3.4 (Pritchard, Stephens \& Donnelly, 2000) software through admixture modeling considering prior information on ancestry from the collection area. For each larva the proportion of ancestry (q) for each of two population clusters is plotted considering prior ancestry information fitting $68 \%$ (A), $20 \%$ (B), or $12 \%$ of the data (C). (D) Discriminant Analysis of Principal Components (DAPC) performed with $R$ package adegenet to show probability membership to three clusters through one discriminant function with an eigen value of 130.6 (40 principal components accumulating 0.925 variance). (E-G) Two discriminant functions obtained from DAPC (with eigen values of 64.72 and 29.34). Dot plot (E) and density plots (F, G) for each function are represented to illustrate overlapping of MED and GOM genetic diversity. 
A

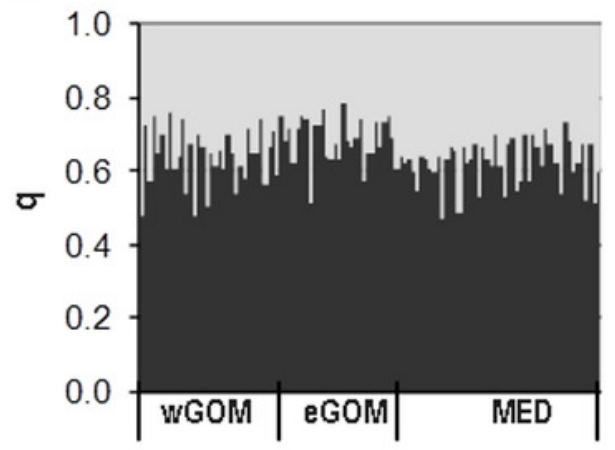

B

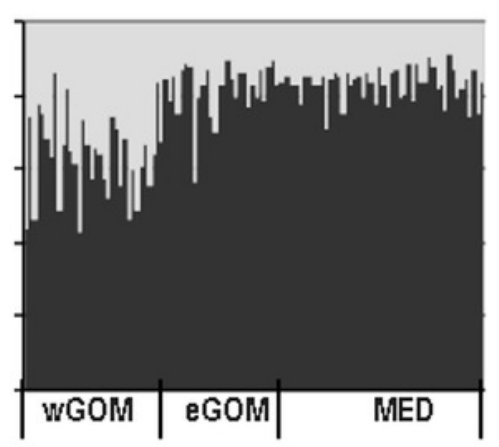

C

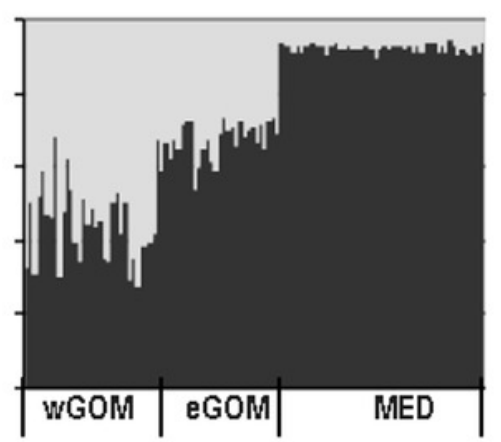

D

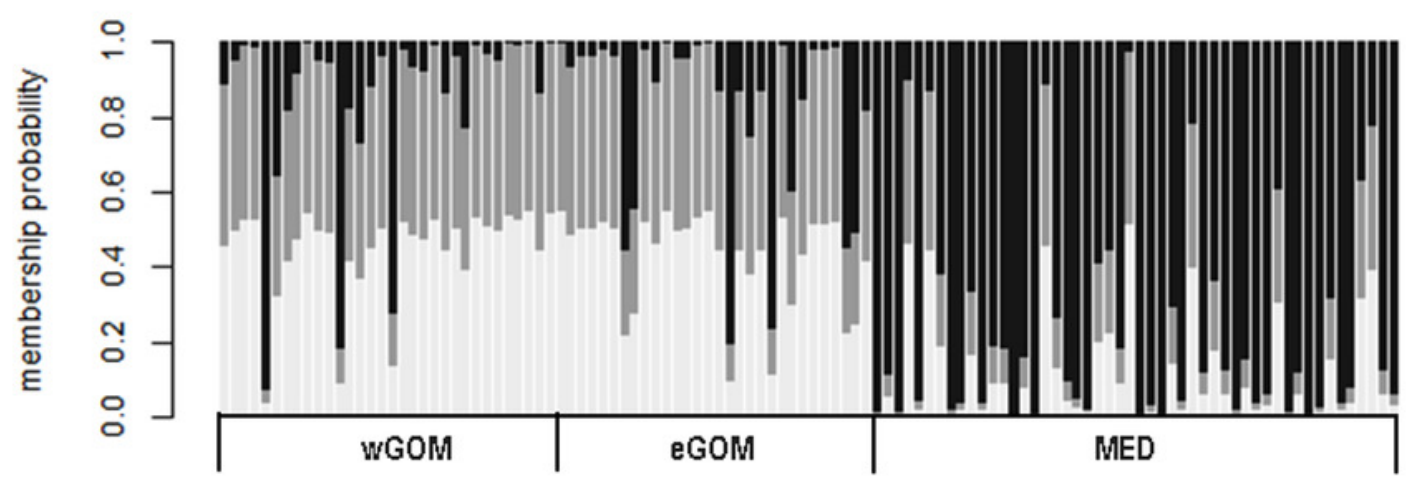

E

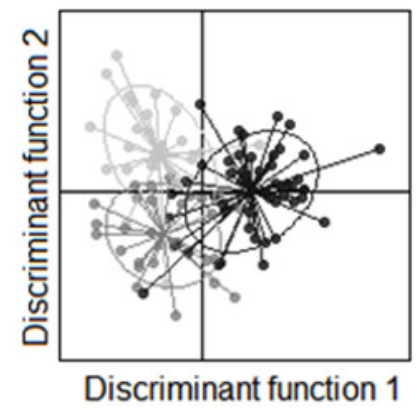

F

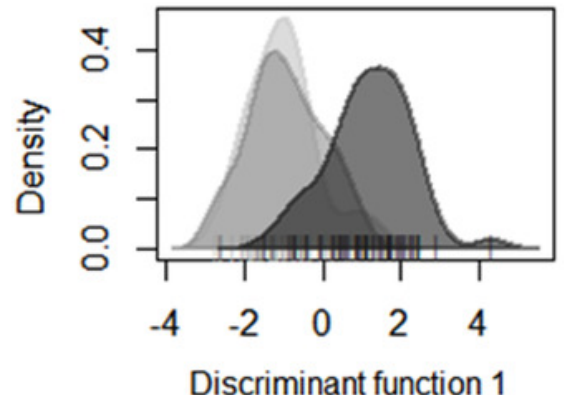

G

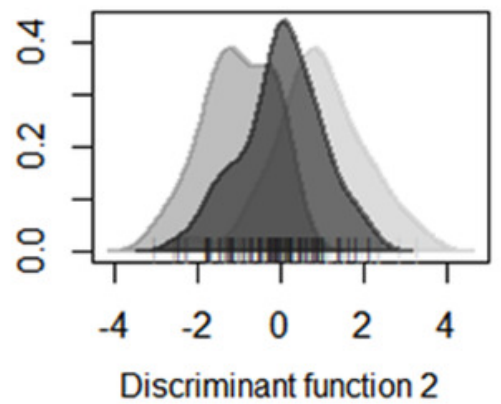

